\title{
Fully Human Monoclonal Antibodies Effectively Neutralizing Botulinum Neurotoxin Serotype B
}

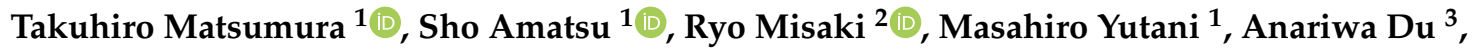 \\ Tomoko Kohda ${ }^{4}$, Kazuhito Fujiyama ${ }^{2}$, Kazuyoshi Ikuta ${ }^{3,5}$ and Yukako Fujinaga ${ }^{1, *}$ \\ 1 Department of Bacteriology, Graduate School of Medical Sciences, Kanazawa University, Takara-machi, \\ Kanazawa, Ishikawa 920-8640, Japan; t-matsu@med.kanazawa-u.ac.jp (T.M.); \\ amatsu@med.kanazawa-u.ac.jp (S.A.); yutanim@med.kanazawa-u.ac.jp (M.Y.) \\ 2 Applied Microbiology Laboratory, International Center for Biotechnology, Osaka University, Yamadaoka, \\ Suita, Osaka 565-0871, Japan; misaki@icb.osaka-u.ac.jp (R.M.); fujiyama@icb.osaka-u.ac.jp (K.F.) \\ 3 Department of Virology, Center for Infectious Disease Control, Research Institute for Microbial Diseases, \\ Osaka University, Yamadaoka, Suita, Osaka 565-0871, Japan; anariwa3100@163.com (A.D.); \\ ikuta@iph.osaka.jp (K.I.) \\ 4 Department of Veterinary Sciences, School of Life and Environmental Sciences, Osaka Prefecture University, \\ Rinkuouraikita, Izumisano, Osaka 598-8531, Japan; kohda@vet.osakafu-u.ac.jp \\ 5 The Japan Science and Technology Agency/Japan International Cooperation Agency, Science and Technology \\ Research Partnership for Sustainable Development, Tokyo 102-0076, Japan \\ * Correspondence: yukafuji@med.kanazawa-u.ac.jp; Tel.: +81-76-265-2200
}

Received: 26 March 2020; Accepted: 4 May 2020; Published: 7 May 2020

check for updates

\begin{abstract}
Botulinum neurotoxin (BoNT) is the most potent natural toxin known. Of the seven BoNT serotypes (A to $G$ ), types A, B, E, and F cause human botulism. Treatment of human botulism requires the development of effective toxin-neutralizing antibodies without side effects such as serum sickness and anaphylaxis. In this study, we generated fully human monoclonal antibodies (HuMAbs) against serotype B BoNT (BoNT/B1) using a murine-human chimera fusion partner cell line named SPYMEG. Of these HuMAbs, M2, which specifically binds to the light chain of BoNT/B1, showed neutralization activity in a mouse bioassay (approximately 10 i.p. $\mathrm{LD}_{50} / 100 \mu \mathrm{g}$ of antibody), and M4, which binds to the C-terminal of heavy chain, showed partial protection. The combination of two HuMAbs, M2 $(1.25 \mu \mathrm{g})$ and M4 $(1.25 \mu \mathrm{g})$, was able to completely neutralize BoNT/B1 (80 i.p. LD 50$)$ with a potency greater than 80 i.p. $\mathrm{LD}_{50} / 2.5 \mu \mathrm{g}$ of antibodies, and was effective both prophylactically and therapeutically in the mouse model of botulism. Moreover, this combination showed broad neutralization activity against three type B subtypes, namely BoNT/B1, BoNT/B2, and BoNT/B6. These data demonstrate that the combination of M2 and M4 is promising in terms of a foundation for new human therapeutics for BoNT/B intoxication.
\end{abstract}

Keywords: Clostridium botulinum; neurotoxin; botulism; fully human monoclonal antibody; SPYMEG; therapeutic effect; preventive effect

Key Contribution: The combination of two fully human monoclonal antibodies (M2+M4) had potent and broad neutralization activity against BoNT/B subtypes, and showed therapeutic and preventive effects against botulism in mouse models. These data indicate that M2+M4 are promising candidates for the development of human therapeutics and prophylactics for BoNT/B intoxication.

\section{Introduction}

Botulinum neurotoxins (BoNTs) produced by the anaerobic bacterium Clostridium botulinum and related species cause botulism, a neuroparalytic disease with high mortality [1,2]. BoNTs have 
been classified as category A agents by the Centers of Disease Control and Prevention (CDC) and are listed among the six agents at highest risk of being used as bioweapons [3]. Originally, seven serotypes, designated A to G, have been identified, and four of these, namely A, B, E, and F, cause human botulism [2]. Additionally, BoNT/DC, which is considered a mosaic toxin between BoNT/D and BoNT/C, has been reported [4,5]. Recently, BoNT/H was reported [6,7], and subsequent studies have described that this toxin is a hybrid-toxin of BoNT/A1 and BoNT/F5 [8-10] and that its light chain and N-terminal of its heavy chain are immunologically unique [11,12]. More recently, the novel serotype BoNT/X [13] and BoNT-like toxin, BoNT/Wo [14] and BoNT/En (BoNT/J) [15,16], were also reported [17].

Each BoNT is synthesized as a single polypeptide chain $(150 \mathrm{kDa})$ that is proteolytically activated by cleavage into a light chain ( $\mathrm{L}$ chain, $50 \mathrm{kDa}$ ) and a heavy chain ( $\mathrm{H}$ chain, $100 \mathrm{kDa})$, which are linked by a disulfide bond [1]. The L chain acts as a zinc metalloprotease. The H chain consists of two functionally distinct regions: the C-terminal, or receptor-binding, domain $\left(\mathrm{H}_{\mathrm{C}}\right)$, and the $\mathrm{N}$-terminal, or translocation, domain $\left(\mathrm{H}_{\mathrm{N}}\right)$.

Food-borne and infant botulism are the primary forms of human botulism [18], and are caused by intestinal absorption of BoNT. BoNT in the gastrointestinal lumen crosses the intestinal barrier [19], enters the blood stream, and reaches the neuromuscular junction. There, BoNT binds via $\mathrm{H}_{C}$ to the receptors present on presynaptic nerve terminals. BoNT/A, BoNT/D, BoNT/E, and BoNT/F bind to synaptic vesicle protein 2 (SV2) and polysialogangliosides [20-22], whereas BoNT/B and BoNT/G bind to synaptotagmin and polysialogangliosides [23,24]; all serotypes subsequently enter neuronal cells by endocytosis. In the acidified synaptic vesicles, $\mathrm{H}_{\mathrm{N}}$ induces translocation of the L chain into the cytosol [25-27]. The metalloprotease domain of the L chain cleaves the soluble $N$-ethylmaleimide-sensitive fusion protein attachment protein receptors (SNAREs) required for synaptic vesicle fusion. The synaptosomal associated protein 25-kDa (SNAP-25) is the target of BoNT/A, BoNT/C, and BoNT/E; synaptobrevin (also known as vesicle-associated membrane protein, VAMP) is the target of BoNT/B, BoNT/D, BoNT/F, and BoNT/G; and syntaxin is the target of BoNT/C $[1,2]$. Cleavage of SNARE inhibits release of the neurotransmitter acetylcholine and leads to paralysis $[1,2]$.

Immunotherapy is the most effective treatment for BoNT intoxication. Equine immune serum formulations are used in cases of human botulism: Botulism-Antitoxin Behring (Novartis Vaccines and Diagnostics $\mathrm{GmbH}$ and Co. KG) is used for treatment of types $\mathrm{A}, \mathrm{B}$, and E, while Botulism Antitoxin Heptavalent (BAT, Cangene Corporation) is used for treatment of types A, B, C, D, E, F, and $\mathrm{G}$. However, because both drugs use heterologous equine proteins, these antisera may cause serum sickness or anaphylaxis. A human immune serum formulation, named BabyBIG (California Department of Public Health) recently became available, but in limited supplies and to treat only infant botulism [18,28]. Additionally, the production of immune sera involves complicated and time-consuming manufacturing processes and quality management. Therefore, the development of safe, effective, and higher productive antibodies is required. Several studies have reported on development of monoclonal antibodies against various BoNT subtypes [29-36], and formulations based on these antibodies are under review by the Food Drug Administration (FDA) in US.

In this study, we generated fully human monoclonal antibodies (HuMAbs) against BoNT/B1, designated M2, M4, and S1, using a murine-human fusion partner cell line named SPYMEG [37-39]. We found that M2 and S1 bound to the L chain of BoNT/B1, and M4 bound to the $\mathrm{H}_{\mathrm{C}}$. Furthermore, M2 showed potent neutralization activity, and the combination of M2 and M4 showed a synergistic neutralization effect. Moreover, this combination provided complete protection against BoNT/B1 in models of both botulism treatment (post-exposure) and prevention (pre-exposure). Finally, we confirmed that this combination also possessed neutralization activity against subtypes BoNT/B2 and BoNT/B6. These results indicate that the combination of M2 and M4 may serve as an effective therapeutic agent for BoNT/B intoxication. 


\section{Results}

\subsection{Immunization with Tetravalent Botulinum Toxoid Vaccine}

Two healthy adult volunteers were inoculated four or five times with a tetravalent botulinum toxoid. At 9 and 18 days after the last vaccination, peripheral blood samples were collected from each volunteer. Plasma antibody titers against BoNT/A1 or BoNT/B1 were measured by enzyme-linked immunosorbent assay (ELISA). In both volunteers, the antibody titers were higher than that of non-vaccinated volunteers as previously reported [40] (Table 1).

Table 1. Antibody titers against BoNT/A1 or BoNT/B1 in plasma samples from volunteers. Antibody titers against BoNT/A1 or BoNT/B1 from the plasma samples of human volunteers were tested using ELISA. Plasma samples were serially diluted two-fold and $50 \mu \mathrm{L}$ of each dilution was added to plates coated with BoNT/A1 or BoNT/B1. After washing, bound HuMAbs were detected by anti-human IgG antibody conjugated with horseradish peroxidase (HRP). ELISA titers are expressed as the highest dilution factor with an absorbance at least twice that of negative control plasma obtained from non-vaccinated volunteers.

\begin{tabular}{ccccc}
\hline $\begin{array}{c}\text { Volunteer } \\
\text { Number }\end{array}$ & $\begin{array}{c}\text { Number of } \\
\text { Vaccinations }\end{array}$ & $\begin{array}{c}\text { Days after Last } \\
\text { Immunization }\end{array}$ & $\begin{array}{c}\text { ELISA Titer }\left(\log _{2}\right) \\
\text { BoNT/A1 }\end{array}$ & $\begin{array}{c}\text { ELISA Titer }\left(\log _{2}\right) \\
\text { BoNT/B1 }\end{array}$ \\
\hline Bkf002 & 5 & 9 & 14 & 13 \\
Bkf002 & 5 & 18 & 13 & 15 \\
Bkf003 & 4 & 9 & 13 & 12 \\
Bkf003 & 4 & 18 & 13 & 14 \\
\hline
\end{tabular}

\subsection{Preparation of $H u M A b s$}

Peripheral blood mononuclear cells (PBMCs) were isolated from peripheral blood samples and fused with SPYMEG cells. After HAT selection, ELISA (first screening) was performed using plates coated with a mixture of BoNT/A1 and BoNT/B1. Twenty-seven and eight positive wells, respectively, were obtained from blood samples collected 9 and 18 days after the last vaccination. These wells were subjected to cell cloning by limiting dilution. Finally, we obtained eight stable hybridoma clones. Isotype analysis showed that four hybridoma clones, designated M1, M2, M4, and S1, produced IgG; three hybridoma clones, designated M3, M5, and M6, produced IgM; and one hybridoma clone, designated M7, produced IgA. Furthermore, an IgG subclass assay revealed that M2, M4, and S1 were each comprised of an IgG1 H chain and L (lambda) chain (Table 2).

Table 2. Isotypes of HuMAbs. ${ }^{*}$ The IgG subclass of M1 could not be determined with the IgG subclass human ELISA kit.

\begin{tabular}{cccc}
\hline Volunteer Number & Days after Last Immunization & Clone No. & Isotype \\
\hline Bkf002 & 9 & M1 & IgG \\
& 9 & M2 & IgG1 \\
& 9 & M3 & IgM \\
9 & M4 & IgG1 \\
& 9 & M5 & IgM \\
& 9 & M6 & IgM \\
& 18 & M7 & IgA \\
Bkf003 & 9 & S1 & IgG1 \\
\hline
\end{tabular}

\subsection{Binding Specificity of HuMAbs}

We selected three IgG1 HuMAbs, namely M2, M4, and S1, and analyzed the binding activity of these HuMAbs against BoNT/A1 and BoNT/B1 by ELISA. All three HuMAbs bound to BoNT/B1, whereas none bound to BoNT/A1 (Figure 1). Each $\mathrm{EC}_{50}$ (HuMAb concentration which showed $50 \%$ of the peak signal on a serial dilution in ELISA) binding affinity to BoNT/B1 were M2: $22.5 \mathrm{ng} / \mathrm{mL}$, M4: $15.3 \mathrm{ng} / \mathrm{mL}$, and S1: $118 \mathrm{ng} / \mathrm{mL}$. We next performed ELISA using recombinant proteins to determine whether the HuMAbs recognized the $\mathrm{L}$ and $\mathrm{H}$ chains $\left(\mathrm{H}_{\mathrm{N}}, \mathrm{H}_{\mathrm{C}}\right)$ of BoNT/B1. M2 and S1 bound to the 
$\mathrm{L}$ chain of BoNT/B1, while M4 bound to the $\mathrm{H}_{\mathrm{C}}$. All three HuMAbs did not bind to $\mathrm{H}_{\mathrm{N}}$ (Figure $2 \mathrm{~A}$ ). To further investigate if the epitopes recognized by HuMAbs overlapped, we performed competitive ELISA. Non-labeled M2 and S1 were equally effective at inhibiting the binding of HRP-labeled M2 to BoNT/B1 and that of binding of HRP-labeled S1 to BoNT/B1, suggesting that M2 and S1 recognized overlapping epitopes. By contrast, binding of HRP-labeled M4 was not inhibited by non-labeled M2 and S1, indicating that M4 recognized a different epitope than M2 and S1 (Figure 2B).
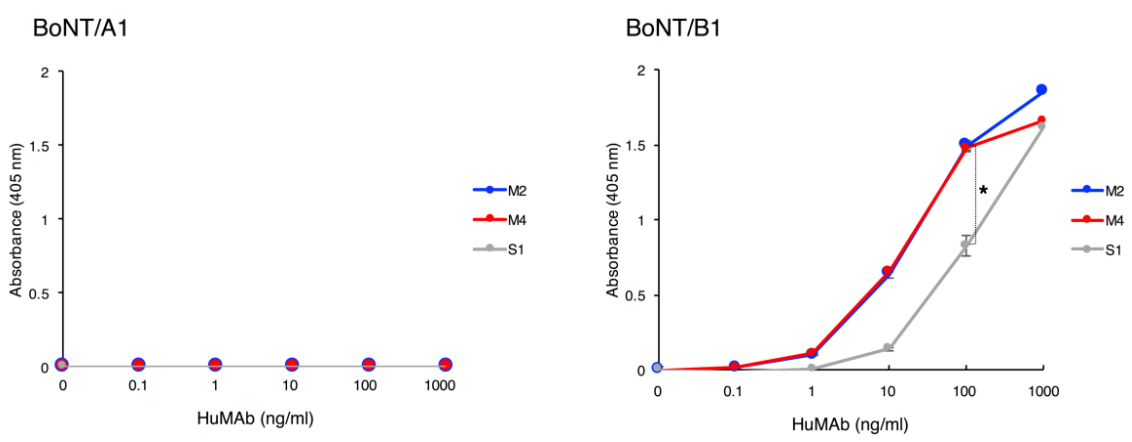

Figure 1. Binding of HuMAbs to BoNT/A1 and BoNT/B1. Binding of HuMAbs to BoNT was analyzed by ELISA. HuMAbs (0.1-1000 ng/mL) were added to plates coated with BoNT/A1 or BoNT/B1. After washing, bound HuMAbs were detected by anti-human IgG antibody conjugated with HRP. Error bars indicate s.d. Statistical analyses were performed with one-way ANOVA followed by Tukey's multiple comparison test $\left({ }^{*} p\right.$-value $\left.<0.01\right)$. Data are representative of three independent experiments.

A
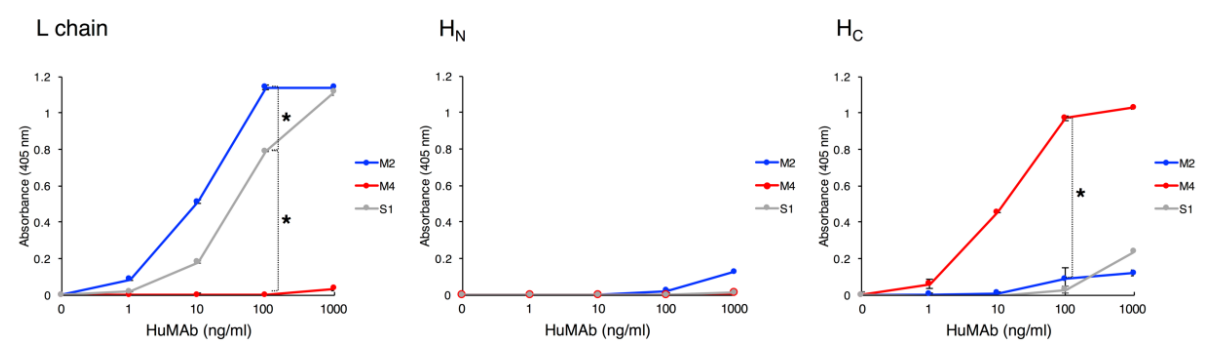

B
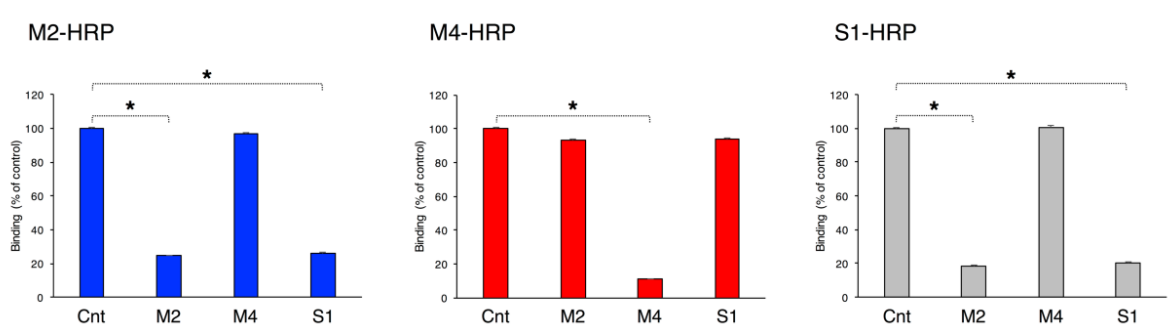

Figure 2. Binding domains of BoNT/B1 recognized by HuMAbs. (A) Binding of HuMAbs to recombinant $\mathrm{L}$ chain, $\mathrm{H}_{\mathrm{N}}$, and $\mathrm{H}_{\mathrm{C}}$ were analyzed by ELISA. HuMAbs $(1.0-1000 \mathrm{ng} / \mathrm{mL})$ were added to plates coated with recombinant $\mathrm{L}$ chain, $\mathrm{H}_{\mathrm{N}}$, or $\mathrm{H}_{\mathrm{C}}$. After washing, bound HuMAbs were detected by anti-human IgG antibody conjugated with HRP. Error bars indicate s.d. Statistical analyses were performed with one-way ANOVA followed by Tukey's multiple comparison test ( $p$-value $<0.01)$. Data are representative of three independent experiments. (B) Binding epitopes of HuMAbs were confirmed by competitive binding ELISA. Non-labeled HuMAbs $(2.5 \mu \mathrm{g} / \mathrm{mL})$ were added to plates coated with BoNT/B1, and then HRP-labeled M2 (1:5000), M4 (1:5000), or S1 (1:1000) was added. Bound HRP-labeled HuMAbs were detected. Results are expressed as percent binding of each HRP-labeled $\mathrm{HuMAb}$, with the $100 \%$ value defined by binding in the absence of non-labeled HuMAbs. Error bars indicate s.d. Statistical analyses were performed with the Student's $t$-test ( ${ }^{*} p$-value $\left.<0.01\right)$. Data are representative of two independent experiments. 


\subsection{Neutralization Activity of HuMAbs}

The neutralization activity of HuMAbs against BoNT/B1 was determined by mouse bioassay. A dose of 10 mouse intraperitoneal (i.p.) lethal dose 50\% (LD $\left.{ }_{50}\right)$ of BoNT/B1 was incubated with $100 \mu \mathrm{g}$ of HuMAb for $1 \mathrm{~h}$ prior to i.p. injection into mice. Control mice treated with PBS died. By contrast, mice treated with M4 were partially protected, as evidenced by an increased time-to-death compared with control mice. Furthermore, complete protection was observed in mice treated with M2 (Figure 3A). Because the S1-producing hybridoma had low productivity, we could not obtain a sufficient quantity of $\mathrm{S} 1$ to test its neutralization activity in the mouse bioassay.

A

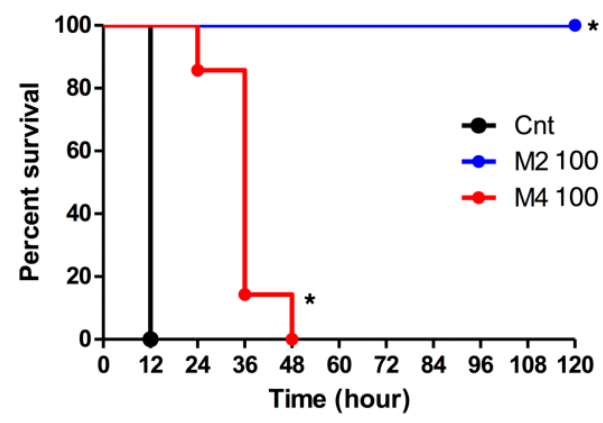

C

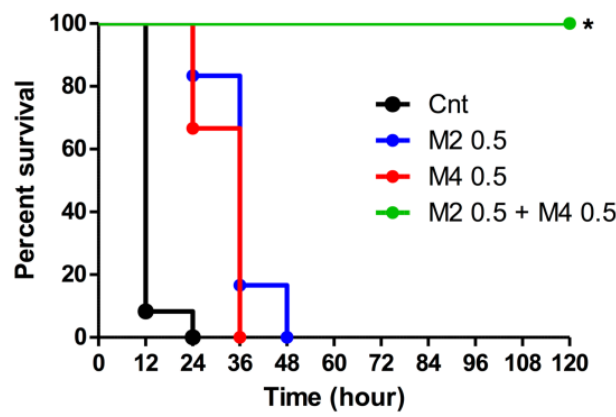

B

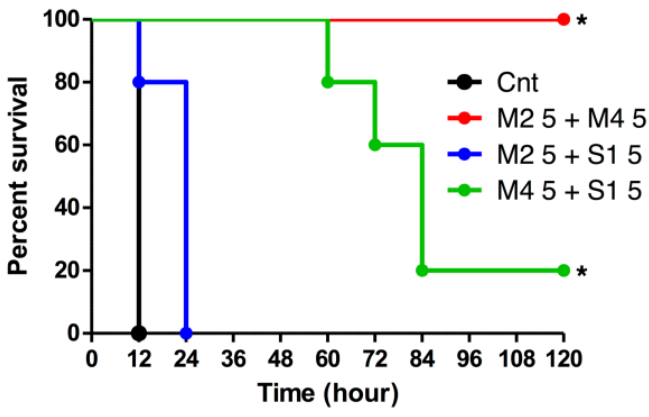

D

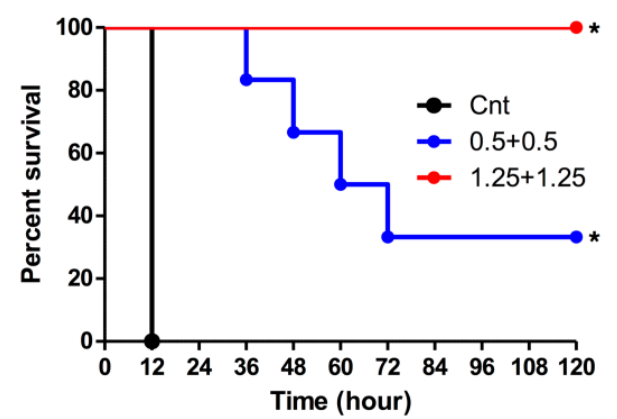

Figure 3. Neutralization activity of HuMAbs against BoNT/B1. The neutralization activity of HuMAbs against BoNT/B1 was determined by mouse bioassay. (A) A dose of 10 i.p. LD 50 of BoNT/B1 was incubated with $100 \mu \mathrm{g}$ of M2 or M4 for $1 \mathrm{~h}$ prior to i.p. injection into mice. Control mice (Cnt) were treated with PBS instead of HuMAbs. Mice were observed for morbidity and mortality for 2 weeks. $n=5$ per group. (B) Neutralization of BoNT/B1 with two combinations of HuMAbs. A dose of 10 i.p. $\mathrm{LD}_{50}$ of BoNT/B1 was incubated with a mixture of HuMAbs (5.0 $\mu \mathrm{g}$ each) and administered by i.p. injection into mice. Control mice (Cnt) were treated with PBS instead of HuMAbs. Mice were observed for morbidity and mortality for 2 weeks. Cnt, $n=10$ per group, M2+M4, $n=5$ per group, M2+S1, $n=5$ per group, M4+S1, $n=5$ per group. (C) Synergistic effect of M2+M4. A dose of 10 i.p. $\mathrm{LD}_{50}$ of BoNT/B1 was incubated with a M2 $(0.5 \mu \mathrm{g}), \mathrm{M} 4(0.5 \mu \mathrm{g})$, or mixture of M2 and M4 (0.5 $\mu \mathrm{g}$ each) and then administered by i.p. injection into mice. Control mice (Cnt) were treated with PBS instead of HuMAbs. Mice were observed for morbidity and mortality for 2 weeks. Cnt, $n=12$ per group, M2 $0.5 \mu \mathrm{g}, n=6$ per group, M4 $0.5 \mu \mathrm{g}, n=6$ per group, $0.5 \mu \mathrm{g}$ each, $n=7$ per group. (D) Neutralization of BoNT/B1 with M2+M4. A dose of 80 i.p. LD $_{50}$ of BoNT/B1 was incubated with a mixture of HuMAbs ( $0.5 \mu \mathrm{g}$ each or $1.25 \mu \mathrm{g}$ each) and administered by i.p. injection into mice. Control mice (Cnt) were treated with PBS instead of HuMAbs. Mice were observed for morbidity and mortality for 2 weeks. Cnt, $n=6$ per group, M2+M4 (0.5 $\mu$ g each), $n=6$ per group, M2+M4 (1.25 $\mu$ g each), $n=6$ per group. The Kaplan-Meier estimator method was used to draw survival curves, and a log-rank test was used to compare the survival rates $\left({ }^{*} p\right.$-value $\left.<0.001\right)$. 
It is known that a combination of monoclonal antibodies shows a synergistic effect neutralizing BoNT [29-36,41-43]. Thus, we next tested for potential synergy of a combination of HuMAbs. A dose of 10 i.p. LD $_{50}$ of BoNT/B1 was incubated with two combinations of HuMAbs (5.0 $\mu$ g each) and injected into mice. The combination of M2 and S1 showed a very weak effect, and the combination of M4 and S1 showed partial protection. By contrast, all of the mice that received the combination of M2 and M4 survived and had no symptoms (Figure 3B). Furthermore, the combination of M2 and M4 $(0.5 \mu \mathrm{g}+0.5 \mu \mathrm{g})$ showed complete protection, although the neutralization activities of single administration $(0.5 \mu \mathrm{g})$ were partially, indicating that this combination acted highly synergistically in neutralizing BoNT/B1 (Figure 3C). Moreover, the combination of M2 and M4 (1.25 $\mathrm{gg}+1.25 \mu \mathrm{g})$ showed complete protection against 80 i.p. LD $_{50}$ (Figure 3D). All surviving mice showed no symptoms in the observation period (2 weeks). Based on these results, we used M2 and M4 in subsequent experiments. We obtained the sequences of the variable domains of the $\mathrm{H}$ and $\mathrm{L}$ chains of these antibodies using reverse transcription polymerase chain reaction (RT-PCR) with consensus primers (Figure 4).

A

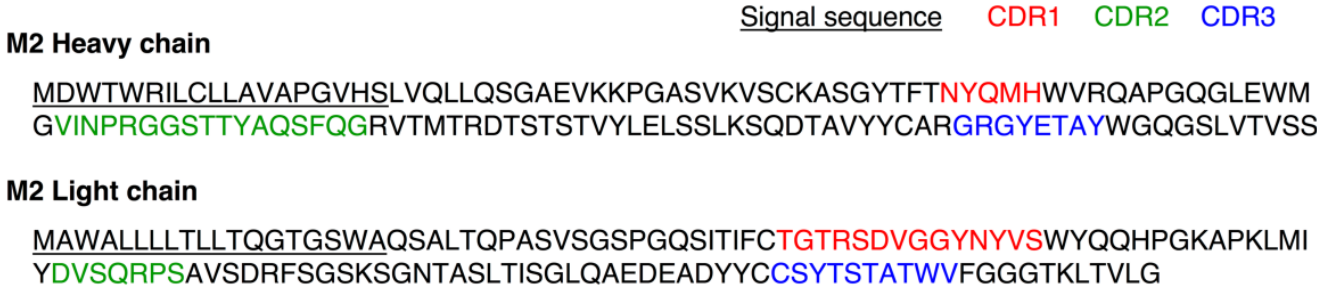

B

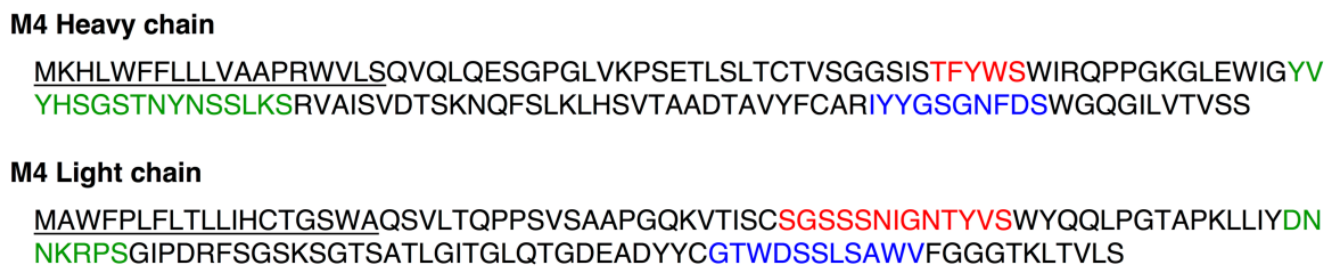
NKRPSGIPDRFSGSKSGTSATLGITGLQTGDEADYYCGTWDSSLSAWVFGGGTKLTVLS

Figure 4. Amino acid sequences of the variable regions of the heavy and light (lambda) chains of (A) M2 and (B) M4. Complementarity-determining regions (CDRs) are indicated in red (CDR1), green (CDR2), and blue (CDR3). Signal sequences are underlined.

BoNTs are always produced along with one or more neurotoxin-associated proteins that non-covalently associate with the BoNT to form progenitor toxin complexes (PTCs). C. botulinum type B strains produce the progenitor toxins M-PTC and L-PTC [44]. M-PTC is composed of BoNT and non-toxic non-HA (NTNHA), whereas L-PTC consists of BoNT, NTNHA, and haemagglutinin (HA). Food-borne botulism and infant botulism are caused by intestinal absorption of these toxin complexes. Therefore, analysis of the neutralization effect of HuMAbs using progenitor toxins is important for development of therapeutic agents for botulism. We tested the therapeutic effect of HuMAbs against orally administrated L-PTC in mice (a post-exposure treatment mouse model). The symptoms of botulism in mice, including fuzzy hair, muscle weakness, and respiratory failure, were observed at 12-24 h after oral ingestion of L-PTC, and untreated mice died. By contrast, complete survival was observed following M2+M4 (0.5 $\mu \mathrm{g}$ each) treatment at $12 \mathrm{~h}$ after oral administration of L-PTC, and partial survival was observed when treatment was given at 24 and $36 \mathrm{~h}$ (Figure 5A). Furthermore, we tested the preventive effect of passive immunization with HuMAbs (a pre-exposure prevention mouse model). In this model, mice were administered i.p. BoNT/B1 (10 i.p. LD50). All non-treated mice died. By contrast, pre-administration with $\mathrm{M} 2+\mathrm{M} 4(0.5 \mu \mathrm{g}$ each) up to 3 days before injection of BoNT/B1 resulted in complete protection against the lethal dose of BoNT/B1. Partial protection was observed in mice administered M2+M4 at 5 or 7 days before BoNT injection (Figure 5B). Changes of botulism symptoms in each mouse in the period of observation are shown in Figure S1. 
A
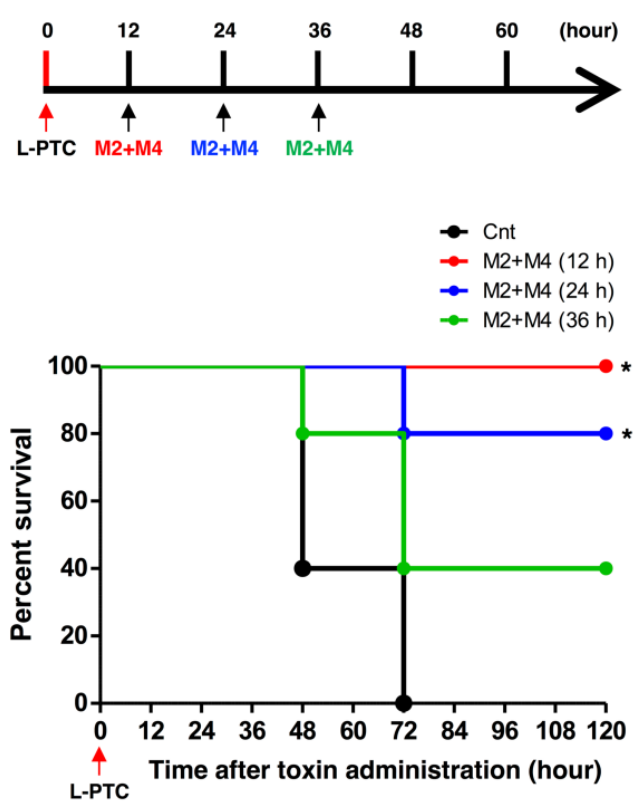

B
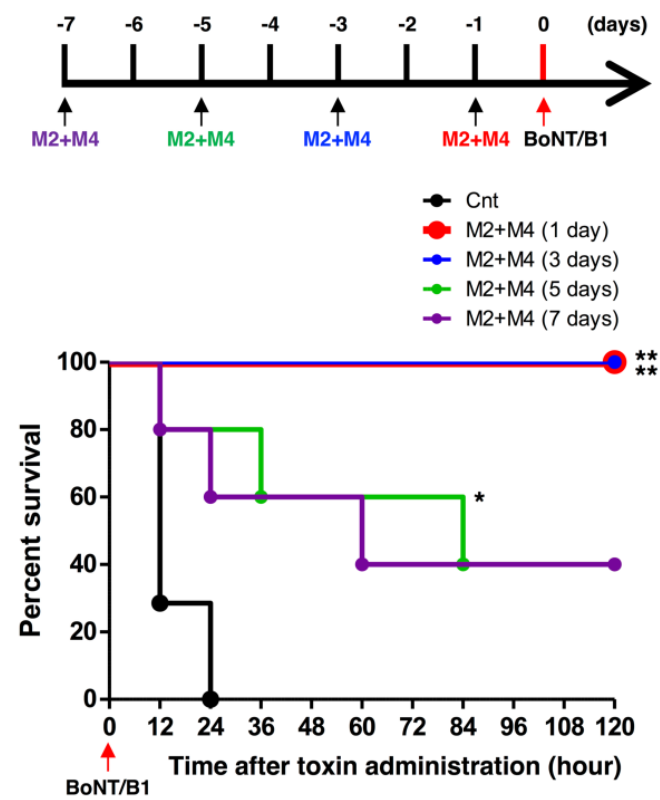

Figure 5. Therapeutic and preventive effects of HuMAbs (M2+M4) against BoNT/B1 intoxication. (A) Mice were orally administered progenitor toxin (L-PTC, $10 \mathrm{ng}$ ), and subsequently administered M2+M4 (0.5 $\mu \mathrm{g}$ each) by i.p. injection at 12, 24, or $36 \mathrm{~h}$ after the oral administration of L-PTC. Control mice (Cnt) were not treated with HuMAbs. Mice were observed for morbidity and mortality for 2 weeks. $n=5$ per group. (B) Mice received i.p. injection of M2+M4 (0.5 $\mu$ g each) and were then challenged at 1, 3, 5, or 7 days later with i.p. administration of 10 i.p. LD $_{50}$ BoNT/B1. Control mice (Cnt) were not injected with HuMAbs. Mice were observed for morbidity and mortality for 2 weeks. Cnt, $n=7$ per group, M2+M4 (1 day), $n=5$ per group, M2+M4 ( 3 days), $n=5$ per group, M2+M4 ( 5 days), $n=5$ per group. M2+M4 (7 days), $n=5$ per group. The Kaplan-Meier estimator method was used to draw survival curves, and a log-rank test was used to compare the survival rates ( $p$-value $<0.01$, ** $p$-value $<0.001)$.

\subsection{Binding and Neutralization Activity of HuMAbs against Subtypes BoNT/B2 and BoNT/B6}

We next tested the breadth of the neutralization activity of M2+M4 by testing their efficacy against subtypes BoNT/B2 and BoNT/B6, which caused infant botulism in Japan [45,46]. ELISA showed that M2 and M4 bound strongly to BoNT/B2 and BoNT/B6 as well as BoNT/B1 (Figure 6A). In the neutralization test, mice injected with $10 \mathrm{ng}$ of BoNT/B2 or $2.5 \mathrm{ng}$ of BoNT/B6 died within $12 \mathrm{~h}$. M2+M4 (0.5 $\mu \mathrm{g}$ each) completely neutralized BoNT/B2 and BoNT/B6 (Figure 6B). All surviving mice showed no symptoms in the observation period. 
A

M2

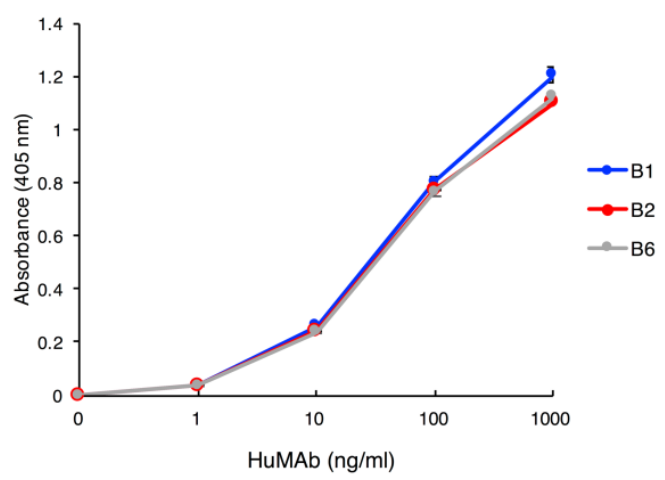

B

BoNT/B2

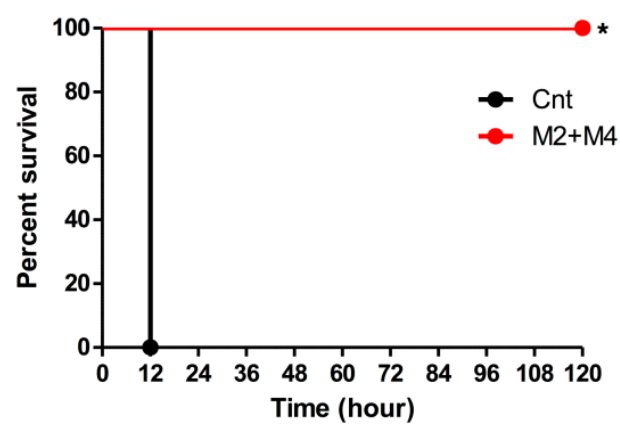

M4

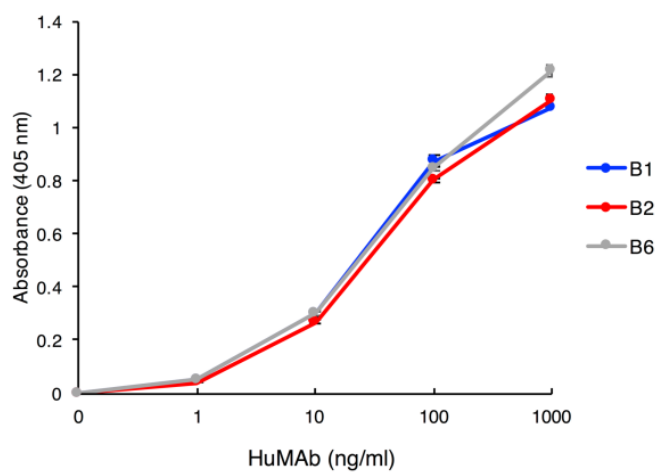

BoNT/B6

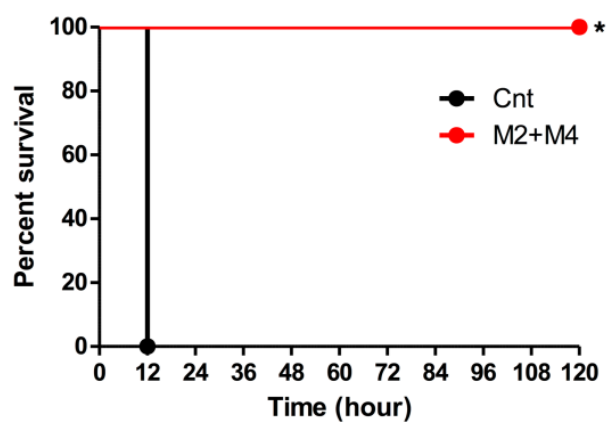

Figure 6. Binding and neutralization activity of HuMAbs against BoNT/B2 and BoNT/B6. (A) Binding of HuMAbs to BoNT/B2 and BoNT/B6 were analyzed by ELISA. HuMAbs (1.0-1000 ng/mL) were added to plates coated with BoNT/B1, BoNT/B2, or BoNT/B6. After washing, bound HuMAbs were detected by anti-human IgG antibody conjugated with HRP. (B) Doses of $10 \mathrm{ng}$ of BoNT/B2 or $2.5 \mathrm{ng}$ of BoNT/B6 were incubated with M2+M4 (0.5 $\mu \mathrm{g}$ each) and administered by i.p. injection into mice. Control mice (Cnt) were treated with PBS instead of HuMAbs. Mice were observed for morbidity and mortality for 2 weeks. $n=5$ per group. The Kaplan-Meier estimator method was used to draw survival curves, and a log-rank test was used to compare the survival rates $\left({ }^{*} p\right.$-value $\left.<0.001\right)$.

\section{Discussion}

Mouse or humanized monoclonal neutralizing antibodies against BoNT/B have been reported in many studies [29,31,43,47-52]. In addition, fully human monoclonal antibodies (HuMAbs) have been shown to effectively neutralize BoNT/B $[35,36,51,52]$, and when used therapeutically in humans, are considered to carry a lower risk of side effects such as serum sickness and anaphylaxis than mouse, humanized, or equine antibodies. Thus, HuMAb therapy may be an effective treatment for human botulism. In this study, we developed fully human monoclonal antibodies specific for BoNT/B using the SPYMEG cell line. We developed nine hybridoma which are producing antibodies against BoNT/B1. We could not obtain BoNT/A1 specific antibody producing hybridoma in this screening. Although the cause of this result is unknown. It could be related to diatheses of volunteers or screening methods. We selected IgG1 (M2, M4, and S1) because IgG1 is the most commonly used subtype for antibody formulations. Among HuMAbs against BoNT/B1, M2 specifically bound to the L chain of BoNT/B1 and showed potent neutralization activity in a mouse bioassay (approximately 10 i.p. $\mathrm{LD}_{50} / 100 \mu \mathrm{g}$ of antibody) (Figure 3A). Mechanistically, M2 may directly inhibit the proteolytic activity of the L chain or prevent the translocation of the $\mathrm{L}$ chain into the cytosol. In fact, both of these mechanisms were reported in a HuMAb that recognized the L chain of BoNT/A [52]. On the other hand, M4 bound to the $\mathrm{H}_{\mathrm{C}}$ (receptor binding domain) and showed partial neutralization activity. M4 may prevent the 
binding of BoNT/B1 to neuronal cells [29]. Meanwhile, the reactivity of M4 with BoNT/B1 was very weak in western blot analysis (denaturing condition) (data not shown). Hence, M4 may recognize the conformational epitope of BoNT/B1. The epitope binding details and neutralization mechanisms of M2 and M4 are currently being analyzed. We are planning to reveal the step of the botulinum neurotoxin mechanism of action that is inhibited by M2 and M4 using neuronal cells, such as PC12 cells.

Several studies have confirmed a synergistic effect when two or more antibodies are combined [29-36,41-43]. In the case of BoNT/B neutralization, to take an example, combination of three mouse monoclonal antibodies (total $2.5 \mu \mathrm{g}$ ) showed complete protection against $80 \mathrm{LD}_{50}$ [48]. We analyzed the neutralization activity of two combinations of HuMAbs to determine the combination with the most potent neutralization activity (Figure 3B). The combination of the HuMAbs (M2+M4), which recognize non-overlapping epitopes, had the most potent neutralization activity among the combinations of M2, M4, and S1, and was able to completely neutralize BoNT/B1 with a potency of 10 i.p. $\mathrm{LD}_{50} / 1.0 \mu \mathrm{g}$ of antibodies (Figure 3C) and 80 i.p. LD $_{50} / 2.5 \mu \mathrm{g}$ of antibodies (Figure 3D). From these results, the combination of "two" HuMAbs, M2+M4 showed neutralization activity against BoNT/B1 approximately equal to the antibodies previously reported which consist of three monoclonal antibodies [48]. It has been suggested that a combination of multiple (three or more) HuMAbs is required to effectively neutralize BoNT/B [35,36,53]. In contrast, two HuMAbs combination, M2+M4 exhibited sufficiently high neutralization activity against BoNT/B1 by the synergistic effect at least in our mouse models. The mechanism of the synergistic effect is unknown. However, the combination of $\mathrm{L}$ chain-binding antibody and $\mathrm{H}_{\mathrm{C}}$-binding antibody might be important for the synergistic effect. By contrast, the combination of M2 and S1, which recognize overlapping epitopes, showed no synergistic effect. This result suggests that the recognition of non-overlapping epitopes is critical for a synergistic effect in BoNT neutralization. Meanwhile, the combination of M4 and S1 showed only partial protection even though M4 and S1 recognize non-overlapping epitopes. The antigen binding affinity of S1 was lower than that of M2 (Figure 1), or the amino acid sequence of BoNT/B1 recognized by $\mathrm{S} 1$ might be slightly different from that of $\mathrm{M} 2$, both of which are factors that may have influenced the synergistic effect of M4+S1.

Food-borne botulism and infant botulism, which account for the majority of cases of human botulism, are caused by the intestinal absorption of the progenitor toxins M-PTC and L-PTC. The oral toxicity of L-PTC is much higher than the toxicity of M-PTC and BoNT individually [19,54]. Thus, L-PTC is considered to be the predominant contributor to the onset of food-borne botulism and presumably infant botulism. In human food-borne botulism, the signs and symptoms of botulism typically begin between 12 and $36 \mathrm{~h}$ after ingestion of the toxin [18]. Therefore, we used a dose of L-PTC at which almost all control mice presented with botulism symptoms approximately $12-24 \mathrm{~h}$ after oral administration of L-PTC. In this mouse model, M2+M4 provided complete protection when administered within $12 \mathrm{~h}$ of oral ingestion of L-PTC, and partial survival was observed at 24 and $36 \mathrm{~h}$ after L-PTC ingestion. Our results show that M2+M4 exerts potent protective activity even after botulism symptoms have developed, but early administration is important. In fact, in the case of food-borne botulism, it is recommended to administer antitoxin as early as possible after toxin exposure. Good treatment outcomes are directly correlated with early administration of antitoxins [18]. Preventive countermeasures against BoNT are also needed for individuals at risk of BoNT exposure, such as first responders in contaminated areas (for example, in instances of bioterrorism or outbreak). Previous studies have reported that passive immunization with HuMAbs protects against the onset of type A botulism [55,56]. In this study, M2+M4 showed a long-term preventive effect against a lethal dose of BoNT/B1 (Figure 5B). It is presumed that because of their low immunogenicity and high affinity to human neonatal Fc receptor compared with mouse antibodies, the HuMAbs M2 and M4 may exist longer in the human bloodstream and therefore neutralize BoNT/B1 more effectively and for a longer period of time [57]. Taken together, these data indicate that M2+M4 has sufficient therapeutic and preventive effects against botulism to permit practical use. 
We also examined the neutralization effect of $\mathrm{M} 2+\mathrm{M} 4$ against other BoNT/B subtypes. For BoNT/B, currently eight subtypes, B1 to B8 are known, with most BoNT/B strain producing B1 and B2 [58-60]. Therefore, we selected BoNT/B2 as an analysis target in addition to BoNT/B1. Furthermore, we also selected BoNT/B6 which caused human botulism similarly to BoNT/B1 and BoNT/B2. The BoNT/B1-producing strain Okra was isolated from a case of food-borne botulism [61]. The BoNT/B2-producing strain 111 and the BoNT/B6-producing strain Osaka05 were isolated from infant botulism cases in Japan [45,46]. BoNT/B2 and BoNT/B6 exhibit toxicies in mice is one-tenth and one-fifth as toxic as BoNT/B1 (BoNT/B2: $1.71 \times 10^{7}$ i.p. LD50/mg protein, BoNT/B6: $2.55 \times 10^{7}$ i.p. $\mathrm{LD}_{50} / \mathrm{mg}$ protein) [62]. BoNT/B2 and BoNT/B6 show different antigenic and biological properties than BoNT/B1 [45,46,61,63]. However, M2 and M4 exhibited strong binding and high neutralization activity against BoNT/B2 and BoNT/B6 as well as against BoNT/B1 (Figure 6). From these results and previous report [62], neutralization activity of $\mathrm{M} 2+\mathrm{M} 4$ is considered to be approximately 171 i.p. $\mathrm{LD}_{50} / 1.0 \mu \mathrm{g}$ of antibodies against BoNT/B2, and approximately 63.75 i.p. LD $_{50} / 1.0 \mu \mathrm{g}$ of antibodies against BoNT/B6. This neutralization activity of $\mathrm{M} 2+\mathrm{M} 4$ against BoNT/B2 may be greater than the antibodies previously reported (BoNT/B2 complexed form, 5.0 LD $50 / 2.5 \mu \mathrm{g}+2.5 \mu \mathrm{g}$ two combination of $\mathrm{IgG}$ ) [50]. These data suggest that M2 and M4 may be effective for the treatment and prevention of botulism caused by broad subtypes of BoNT/B. Meanwhile, BoNT/B4, produced by non-proteolytic C. botulinum (group II), is the most dissimilar among all the BoNT/B subtypes so far and differs from BoNT/B1 by $6.8 \%$ at the amino acid level [60]. Further analysis on the neutralization effect against other subtypes of BoNT/B including BoNT/B4 would strengthen this proposition.

\section{Conclusions}

We developed anti-BoNT/B antibody-producing hybridomas using the SPYMEG cell line, and obtained two neutralizing antibodies, M2 and M4. This method can be applied to other botulinum serotypes, and it will be possible to maintain a stable supply of HuMAbs using these hybridomas. Because of their human origin, M2 and M4 are safe for the treatment of human botulism, including infant botulism. Furthermore, we found that the combination of M2 and M4 had potent neutralization activity against BoNT/B1 in spite of only two HuMAbs, and neutralized two other subtypes. Additionally, $\mathrm{M} 2+\mathrm{M} 4$ showed therapeutic and preventive effects against botulism in mouse models. These data indicate that the fully human monoclonal antibodies, M2 and M4, are one of the promising candidates for the development of human therapeutics and prophylactics for BoNT/B intoxication.

\section{Materials and Methods}

\subsection{Ethics Statement}

Human materials were collected using protocols approved by the Institutional Review Board of the Osaka University Research Institute for Microbial Diseases (\#20-8, approved on 8 April 2009). Written informed consent was obtained from the participants. Animal studies were conducted under the applicable laws and guidelines for the care and use of laboratory animals at the Osaka University Research Institute for Microbial Diseases and Kanazawa University. They were approved by the Animal Experiment Committee of the Osaka University Research Institute for Microbial Diseases (\#H21-27-0, approved on 19 February 2010, \#H27-02-0, approved on 30 April 2015) and Kanazawa University (AP-163710, approved on 15 March 2016).

\subsection{Preparation of $B o N T / A$ and $B o N T / B$}

C. botulinum serotype B1 strain Okra was cultured for 5 days at $35{ }^{\circ} \mathrm{C}$ using a cellophane tube procedure [dialysis outer liquid: 3\% pepton (Sigma-Aldrich, St. Louis, MO, USA), 6\% polypepton (FUJIFILM, Osaka, Japan), 6\% lactalbumin hydrolysate (FUJIFILM), 3\% yeast extract (Becton, Dickinson and Company, Sparks, MD, USA), dialysis inner liquid: 10\% glucose (FUJIFILM), 5\% NaCl (FUJIFILM), $1 \%$ L-cysteine hydrochloride monohydrate (FUJIFILM)], and the culture supernatant was obtained. 
The culture supernatant was concentrated by $60 \%$ ammonium sulfate precipitation. After dialysis, progenitor toxins (M-PTC and L-PTC) were purified from the culture supernatant using an SP-Toyopearl $650 \mathrm{M}$ column (Tosoh, Tokyo, Japan) and a lactose gel column (EY Laboratories, San Mateo, CA, USA). BoNT/B1 and a non-toxic component were prepared from L-PTC using the lactose gel column under alkaline conditions of $\mathrm{pH}$ 8.0, as described previously [64]. The lethal toxicity of BoNT/B1 was determined using mouse bioassay [65,66]. BoNT/A1 (strain 62A), BoNT/B2 (strain 111), and BoNT/B6 (strain Osaka05) were provided by Dr. T. Kohda (Osaka Prefecture University).

\subsection{Inoculation of Botulinum Toxoid Vaccine}

Two healthy adult volunteers were inoculated four or five times with a tetravalent botulinum toxoid vaccine (types A, B, E, and F) [40] provided by Dr. M. Takahashi (National Institute of Infectious Diseases). The toxoid was injected intramuscularly in $0.5-\mathrm{mL}$ doses. Blood samples were collected from each volunteer and the plasma antibody titers against BoNT/A1 and BoNT/B1 were tested by ELISA.

\subsection{Preparation of HuMAbs}

Peripheral blood samples $(10 \mathrm{~mL})$ were collected from volunteers 9 or 18 days after the last immunization, and PBMCs were purified by Ficoll (GE Healthcare, Buckinghamshire, UK) gradient centrifugation. The PBMCs were fused with cells from the mouse-human fusion partner cell line SPYMEG (Medical \& Biological Laboratories, Nagoya, Japan) at a ratio of 10:1 with polyethylene glycol (Roche, Basel, Switzerland). Fused cells were cultured in Dulbecco's modified Eagle medium (DMEM, Thermo Fisher Scientific, Waltham, MA, USA) supplemented with $15 \%$ heat-inactivated fetal bovine serum in 96-well plates for 10-14 days in the presence of hypoxanthine-aminopterin-thymidine (HAT, Thermo Fisher Scientific). The first screening of the culture medium for antibodies specific to BoNT/A1 or BoNT/B1 was performed by ELISA. BoNT/A1 or BoNT/B1-specific antibody-positive wells were next subjected to cell cloning by limiting dilution. Hybridomas were collected, diluted in medium, and then used to seed new plates (1-2 cells/well) to obtain a monoclonal cell population. The plates were incubated for 10-14 days. The second screening was also performed by ELISA. After cell cloning, cultures of BoNT/A1 or BoNT/B1-specific antibody producing-hybridomas were scaled up and we made cell stocks. Each stable hybridoma was cultured in serum-free medium (Thermo Fisher Scientific), and then the supernatant was collected. Isotypes of HuMAbs in culture supernatant were determined by western blot using anti-human IgG conjugated with HRP (Bio-Rad Laboratories, Berkeley, CA, USA), anti-human IgM conjugated with HRP (Invitrogen, Carlsbad, CA, USA), or anti-human IgA conjugated with HRP (Invitrogen). IgG antibodies were purified from the supernatant using a Protein G column (GE Healthcare). The concentration of IgG was determined by BCA Protein Assay Kit (Thermo Fisher Scientific). The subclass of each IgG antibody was determined using a human IgG subclass ELISA kit (Invitrogen).

\subsection{Preparation of Recombinant Proteins}

Purified DNA from C. botulinum type B strain Okra was used as a template for the amplification of DNA encoding L chain (aa 1-430), $\mathrm{H}_{\mathrm{N}}$ (aa 449-858), and $\mathrm{H}_{\mathrm{C}}$ (aa 858-1291) by PCR. The amplified DNAs were inserted into NcoI- XhoI site of the pET28b vector (Novagen, Merck Millipore, Madison, WI, USA). Recombinant proteins were expressed as C-terminally His-tagged proteins in E. coli strain BL21-CodonPlus (DE3)-RIL (Agilent Technologies, Santa Clara, CA, USA). Protein expression was induced using Overnight Express ${ }^{\mathrm{TM}}$ Autoinduction System 1 (Merck Millipore). E. coli were cultured for $48 \mathrm{~h}$ at $18{ }^{\circ} \mathrm{C}$ or $36 \mathrm{~h}$ at $30{ }^{\circ} \mathrm{C}$, and then were harvested. Bacterial cells were sonicated, and purified recombinant proteins from extracts using HisTrap HP (GE Healthcare). The concentration of recombinant protein was determined by BCA Protein Assay Kit. 


\subsection{Binding Assay Using ELISA}

The 96-well plates (Corning, Corning, NY, USA) were coated with BoNT, recombinant $\mathrm{L}$ chain, recombinant $\mathrm{H}_{\mathrm{N}}$, or recombinant $\mathrm{H}_{\mathrm{C}}(300 \mathrm{ng} /$ well $)$ for $2 \mathrm{~h}$ at $37^{\circ} \mathrm{C}$. The wells were washed three times with phosphate-buffered saline (PBS) containing 0.05\% Tween20 (Sigma-Aldrich) (PBS-T) and blocked with $0.2 \%$ bovine serum albumin (BSA, Sigma-Aldrich)/PBS-T overnight at $4{ }^{\circ} \mathrm{C}$. Human plasma samples or HuMAbs were added to a well and incubated for $2 \mathrm{~h}$ at $37^{\circ} \mathrm{C}$. After washing three times, anti-human IgG conjugated with HRP (Bio-Rad Laboratories or Jackson ImmunoResearch, West Grove, PA, USA) was added and incubated for $2 \mathrm{~h}$ at $37^{\circ} \mathrm{C}$. Plates were washed three times again and then incubated with substrate solution (o-phenylendiamine, Nacalai Tesque, Kyoto, Japan or ABTS, Roche) for $20 \mathrm{~min}$ at $37^{\circ} \mathrm{C}$, and absorbance values at $\mathrm{Abs}_{492}$ or $\mathrm{Abs}_{405}$ were measured, respectively.

\subsection{Competition ELISA}

M2, M4, and S1 were labeled with HRP using Perioxidase Labeling Kits (Dojindo Molecular Technologies, Kumamoto, Japan). The optimal dilutions of HRP-labeled HuMAbs were determined by ELISA based on an $\mathrm{Abs}_{405}$ value around 2.0. Non-labeled HuMAb $(2.5 \mu \mathrm{g} / \mathrm{mL})$ was added to plates coated with BoNT/B1 and incubated for $2 \mathrm{~h}$ at $37^{\circ} \mathrm{C}$. After washing, HRP-labeled M2 (1:5000), M4 (1:5000), or S1 (1:1000) was added and incubated for $2 \mathrm{~h}$ at $37^{\circ} \mathrm{C}$. Plates were washed again and incubated with substrate solution (ABTS) for $20 \mathrm{~min}$ at $37^{\circ} \mathrm{C}$, and absorbance values at $\mathrm{Abs}_{405}$ were measured.

\subsection{Sequencing of HuMAb Variable Region Gene Segments}

Total RNA was extracted from the hybridomas using an RNeasy Mini Kit (Qiagen, Hilden, Germany), and cDNA was synthesized by RT-PCR using a SuperScript ${ }^{\circledR}$ VILO $^{\text {TM }}$ CDNA Synthesis Kit (Invitrogen). The coding regions of the $\mathrm{H}$ and $\mathrm{L}$ chains of $\mathrm{M} 2$ and $\mathrm{M} 4$ were amplified by PCR using KOD-Plus-Neo (TOYOBO, Osaka, Japan), with the following primers: 5'-ATGGACTGGACCTGGAGGATCCTC-3' (M2 $\mathrm{H}$ chain sense primer), 5'-ATGAAACACCTGTGGTTCTTCCTCCT-3' (M4 H chain sense primer), and 5'-CTCCCGCGGCTTTGTCTTGGCATTA-3' (H chain antisense primer); and 5'-ATGSCCTGGGCTCYKCTSCTCCTS-3' (M2 L chain sense primer), 5'-ATGGCCTGGW YYCCTCTCYTYCTS-3' (M4 L chain sense primer), and 5'-TGGCAGCTGTAGCTTCTGTGGGACT-3' ( $\mathrm{L}$ chain antisense primer).

\subsection{Neutralization Test (Mouse Bioassay)}

The neutralization activity of HuMAbs was tested by mouse bioassay. Female ddY mice were purchased from SLC (Shizuoka, Japan) and were used at 4 weeks of age. $10 \mathrm{mM}$ sodium phosphate buffer ( $\mathrm{pH}$ 6.0) containing $0.1 \%$ gelatin was used for sample dilution. One or more HuMAbs was incubated with BoNT/B1, BoNT/B2, or BoNT/B6 at room temperature for $1 \mathrm{~h}$ prior to i.p. injection (in a total volume of $500 \mu \mathrm{L}$ ) into mice. In control mice, BoNT was incubated with PBS instead of HuMAbs. In the botulism treatment (post-exposure) model, the B1 subtype progenitor toxin (L-PTC, $10 \mathrm{ng}$ in a volume of $300 \mu \mathrm{L}$ ) was orally administered and M2+M4 was subsequently administered at 12, 24, and $36 \mathrm{~h}$ after oral administration of L-PTC by i.p. injection. In the botulism prevention (pre-exposure) model, M2+M4 was administered by i.p. injection and mice were then challenged at 1, 3, 5, or 7 days later with 10 i.p. $\mathrm{LD}_{50}$ BoNT/B1 by i.p. injection. Mice were observed for morbidity and mortality for 2 weeks.

Supplementary Materials: The following are available online at http://www.mdpi.com/2072-6651/12/5/302/s1, Figure S1: Therapeutic and preventive effects of HuMAbs (M2+M4) against BoNT/B1 intoxication: Changes of botulism symptoms in each mouse in the period of observation ( 2 weeks). 
Author Contributions: Conceptualization: T.M. and Y.F.; methodology, T.M., S.A., R.M., M.Y., A.D., K.F., K.I., and Y.F.; formal analysis, T.M., S.A., R.M., M.Y. and A.D.; investigation, T.M., S.A. and M.Y.; resources, S.A., R.M., A.D., T.K., K.F. and K.I.; data curation, T.M.; writing—original draft preparation, T.M.; writing—review and editing, Y.F.; supervision, Y.F.; project administration, K.I. and Y.F.; funding acquisition, K.I. and Y.F.; All authors participated in discussion of the data and in production of the final version of the manuscript.

Funding: This work was supported by the Japan Science and Technology Agency/Japan International Cooperation Agency, Science and Technology Research Partnership for Sustainable Development, 08080924 (JST/JICA, SATREPS) (http://www.jst.go.jp/global/english/kadai/h2011_thailand.html), the Japan Agency for Medical Research and Development, AMED (Grant No. 19fk0108101h0501), and the Japan Society for the Promotion of Science KAKENHI (Grant No. 16K19123, 18K07107 and No. 18H02654).

Acknowledgments: We would like to thank Y. Sugawara, A. Sano, K. Sasaki, and C. Aoki (Research Institute for Microbial Diseases, Osaka University, Japan); K. Hosomi (Department of Veterinary Sciences, School of Life and Environmental Sciences, Osaka Prefecture University, Japan); and S. Akagi, Y. Koino, M. Kitamura, C. Morimoto and K. Imazaki (Department of Bacteriology, Graduate School of Medical Sciences, Kanazawa University, Japan) for their technical assistance. We also thank T. Kenri, A. Yamamoto, and M. Iwaki (Department of Bacteriology II, National Institute of Infectious Diseases, Japan) for advice on the mouse bioassay. Finally, we thank S. Kozaki (Department of Veterinary Sciences, School of Life and Environmental Sciences, Osaka Prefecture University, Japan) for advice on botulinum toxins, M. Takahashi (Department of Bacteriology II, National Institute of Infectious Diseases, Japan) for providing the toxoid vaccine, and M. Yasugi and R. Kubota-Koketsu (Research Institute for Microbial Diseases, Osaka University, Japan) for advice on the SPYMEG cell line and cell fusion.

Conflicts of Interest: The authors declare no competing financial interests.

\section{References}

1. Schiavo, G.; Matteoli, M.; Montecucco, C. Neurotoxins affecting neuroexocytosis. Physiol. Rev. 2000, 80, 717-766. [CrossRef]

2. Rossetto, O.; Pirazzini, M.; Montecucco, C. Botulinum neurotoxins: Genetic, structural and mechanistic insights. Nat. Rev. Genet. 2014, 12, 535-549. [CrossRef] [PubMed]

3. Froude, J.W.; Stiles, B.G.; Pelat, T.; Thullier, P. Antibodies for biodefense. $m A$ bs 2011, 3, 517-527. [CrossRef] [PubMed]

4. Nakamura, K.; Kohda, T.; Shibata, Y.; Tsukamoto, K.; Arimitsu, H.; Hayashi, M.; Mukamoto, M.; Sasakawa, N.; Kozaki, S. Unique Biological Activity of Botulinum D/C Mosaic Neurotoxin in Murine Species. Infect. Immun. 2012, 80, 2886-2893. [CrossRef] [PubMed]

5. Zhang, S.; Berntsson, R.; Tepp, W.H.; Tao, L.; Johnson, E.A.; Stenmark, P.; Dong, M. Structural basis for the unique ganglioside and cell membrane recognition mechanism of botulinum neurotoxin DC. Nat. Commun. 2017, 8, 1637. [CrossRef]

6. Barash, J.R.; Arnon, S.S. A Novel Strain of Clostridium botulinum That Produces Type B and Type H Botulinum Toxins. J. Infect. Dis. 2013, 209, 183-191. [CrossRef]

7. Dover, N.; Barash, J.R.; Hill, K.; Xie, G.; Arnon, S.S. Molecular Characterization of a Novel Botulinum Neurotoxin Type H Gene. J. Infect. Dis. 2013, 209, 192-202. [CrossRef]

8. Maslanka, S.E.; Lúquez, C.; Dykes, J.K.; Tepp, W.H.; Pier, C.L.; Pellett, S.; Raphael, B.; Kalb, S.R.; Barr, J.R.; Rao, A.; et al. A Novel Botulinum Neurotoxin, Previously Reported as Serotype H, Has a Hybrid-Like Structure With Regions of Similarity to the Structures of Serotypes A and F and Is Neutralized With Serotype A Antitoxin. J. Infect. Dis. 2015, 213, 379-385. [CrossRef]

9. Fan, Y.; Barash, J.R.; Lou, J.; Conrad, F.; Marks, J.D.; Arnon, S.S. Immunological Characterization and Neutralizing Ability of Monoclonal Antibodies Directed Against Botulinum Neurotoxin Type, H. J. Infect. Dis. 2016, 213, 1606-1614. [CrossRef]

10. Yao, G.; Lam, K.-H.; Perry, K.; Weisemann, J.; Rummel, A.; Jin, R. Crystal Structure of the Receptor-Binding Domain of Botulinum Neurotoxin Type HA, Also Known as Type FA or H. Toxins 2017, 9, 93. [CrossRef]

11. Lam, K.-H.; Sikorra, S.; Weisemann, J.; Maatsch, H.; Perry, K.; Rummel, A.; Binz, T.; Jin, R. Structural and biochemical characterization of the protease domain of the mosaic botulinum neurotoxin type HA. Pathog. Dis. 2018, 76, 76. [CrossRef] [PubMed]

12. Fan, Y.; Barash, J.R.; Conrad, F.; Lou, J.; Tam, C.; Cheng, L.W.; Arnon, S.S.; Marks, J.D. The Novel Clostridial Neurotoxin Produced by Strain IBCA10-7060 Is Immunologically Equivalent to BoNT/HA. Toxins 2019, 12, 9. [CrossRef] [PubMed] 
13. Zhang, S.; Masuyer, G.; Zhang, J.; Shen, Y.; Lundin, D.; Henriksson, L.; Miyashita, S.-I.; Martínez-Carranza, M.; Dong, M.; Stenmark, P. Identification and characterization of a novel botulinum neurotoxin. Nat. Commun. 2017, 8, 14130. [CrossRef] [PubMed]

14. Zornetta, I.; Tehran, D.A.; Arrigoni, G.; Anniballi, F.; Bano, L.; Leka, O.; Zanotti, G.; Binz, T.; Montecucco, C. The first non Clostridial botulinum-like toxin cleaves VAMP within the juxtamembrane domain. Sci. Rep. 2016, 6, 30257. [CrossRef]

15. Brunt, J.; Carter, A.T.A.T.; Stringer, S.C.S.C.; Peck, M. Identification of a novel botulinum neurotoxin gene cluster in Enterococcus. FEBS Lett. 2018, 592, 310-317. [CrossRef]

16. Zhang, S.; Lebreton, F.; Mansfield, M.J.; Miyashita, S.-I.; Zhang, J.; Schwartzman, J.A.; Tao, L.; Masuyer, G.; Martínez-Carranza, M.; Stenmark, P.; et al. Identification of a Botulinum Neurotoxin-like Toxin in a Commensal Strain of Enterococcus faecium. Cell Host Microbe 2018, 23, 169-176.e6. [CrossRef]

17. Tehran, D.A.; Pirazzini, M. Novel Botulinum Neurotoxins: Exploring Underneath the Iceberg Tip. Toxins 2018, 10, 190. [CrossRef]

18. Arnon, S.S.; Schechter, R.; Inglesby, T.V.; Henderson, D.A.; Bartlett, J.G.; Ascher, M.S.; Eitzen, E.; Fine, A.D.; Hauer, J.; Layton, M.; et al. Botulinum toxin as a biological weapon: Medical and public health management. JAMA 2001, 285, 1059-1070. [CrossRef]

19. Matsumura, T.; Sugawara, Y.; Yutani, M.; Amatsu, S.; Yagita, H.; Kohda, T.; Fukuoka, S.-I.; Nakamura, Y.; Fukuda, S.; Hase, K.; et al. Botulinum toxin A complex exploits intestinal M cells to enter the host and exert neurotoxicity. Nat. Commun. 2015, 6, 6255. [CrossRef]

20. Dong, M. SV2 Is the Protein Receptor for Botulinum Neurotoxin, A. Science 2006, 312, 592-596. [CrossRef]

21. Dong, M.; Liu, H.; Tepp, W.H.; Johnson, E.A.; Janz, R.; Chapman, E.R. Glycosylated SV2A and SV2B Mediate the Entry of Botulinum Neurotoxin E into Neurons. Mol. Boil. Cell 2008, 19, 5226-5237. [CrossRef] [PubMed]

22. Fu, Z.; Chen, C.; Barbieri, J.T.; Kim, J.-J.P.; Baldwin, M.R. Glycosylated SV2 and Gangliosides as Dual Receptors for Botulinum Neurotoxin Serotype, F. Biochemistry 2009, 48, 5631-5641. [CrossRef] [PubMed]

23. Nishiki, T.; Kamata, Y.; Nemoto, Y.; Omori, A.; Ito, T.; Takahashi, M.; Kozaki, S. Identification of protein receptor for Clostridium botulinum type B neurotoxin in rat brain synaptosomes. J. Boil. Chem. 1994, 269, 10498-10503.

24. Nishiki, T.-I.; Tokuyama, Y.; Kamata, Y.; Nemoto, Y.; Yoshida, A.; Sato, K.; Sekiguchi, M.; Takahashi, M.; Kozaki, S. The high-affinity binding ofClostridium botulinumtype B neurotoxin to synaptotagmin II associated with gangliosides GT1b/GD1a. FEBS Lett. 1996, 378, 253-257. [CrossRef]

25. Hoch, D.H.; Romero-Mira, M.; Ehrlich, B.E.; Finkelstein, A.; Dasgupta, B.R.; Simpson, L.L. Channels formed by botulinum, tetanus, and diphtheria toxins in planar lipid bilayers: Relevance to translocation of proteins across membranes. Proc. Natl. Acad. Sci. USA 1985, 82, 1692-1696. [CrossRef]

26. Koriazova, L.K.; Montal, M. Translocation of botulinum neurotoxin light chain protease through the heavy chain channel. Nat. Genet. 2003, 10, 13-18. [CrossRef]

27. Pirazzini, M.; Tehran, D.A.; Zanetti, G.; Rossetto, O.; Montecucco, C. Hsp90 and Thioredoxin-Thioredoxin Reductase enable the catalytic activity of Clostridial neurotoxins inside nerve terminals. Toxicon 2018, 147, 32-37. [CrossRef]

28. Arnon, S.S.; Schechter, R.; Maslanka, S.E.; Jewell, N.P.; Hatheway, C.L. Human Botulism Immune Globulin for the Treatment of Infant Botulism. N. Engl. J. Med. 2006, 354, 462-471. [CrossRef]

29. Chen, C.; Wang, S.; Wang, H.; Mao, X.; Zhang, T.; Ji, G.; Shi, X.; Xia, T.; Lu, W.; Zhang, D.; et al. Potent Neutralization of Botulinum Neurotoxin/B by Synergistic Action of Antibodies Recognizing Protein and Ganglioside Receptor Binding Domain. PLoS ONE 2012, 7, e43845. [CrossRef]

30. Nayak, S.U.; Griffiss, J.M.; McKenzie, R.; Fuchs, E.J.; Jurao, R.A.; An, A.T.; Ahene, A.; Tomic, M.; Hendrix, C.W.; Zenilman, J.M. Safety and Pharmacokinetics of XOMA 3AB, a Novel Mixture of Three Monoclonal Antibodies against Botulinum Toxin A. Antimicrob. Agents Chemother. 2014, 58, 5047-5053. [CrossRef]

31. Fan, Y.; Dong, J.; Lou, J.; Wen, W.; Conrad, F.; Geren, I.N.; Garcia-Rodriguez, C.; Smith, T.J.; Smith, L.A.; Ho, M.; et al. Monoclonal Antibodies that Inhibit the Proteolytic Activity of Botulinum Neurotoxin Serotype/B. Toxins 2015, 7, 3405-3423. [CrossRef] [PubMed]

32. Fan, Y.; Garcia-Rodriguez, C.; Lou, J.; Wen, W.; Conrad, F.; Zhai, W.; Smith, T.J.; Smith, L.A.; Marks, J.D. A three monoclonal antibody combination potently neutralizes multiple botulinum neurotoxin serotype $\mathrm{F}$ subtypes. PLoS ONE 2017, 12, e0174187. [CrossRef] [PubMed] 
33. Garcia-Rodriguez, C.; Razai, A.; Geren, I.N.; Lou, J.; Conrad, F.; Wen, W.-H.; Farr-Jones, S.; Smith, T.J.; Brown, J.L.; Skerry, J.C.; et al. A Three Monoclonal Antibody Combination Potently Neutralizes Multiple Botulinum Neurotoxin Serotype E Subtypes. Toxins 2018, 10, 105. [CrossRef] [PubMed]

34. Snow, D.M.; Riling, K.; Kimbler, A.; Espinoza, Y.; Wong, D.; Pham, K.; Martinez, Z.; Kraus, C.N.; Conrad, F.; Garcia-Rodriguez, C.; et al. Safety and Pharmacokinetics of a Four Monoclonal Antibody Combination against Botulinum C and D Neurotoxins. Antimicrob. Agents Chemother. 2019, 63. [CrossRef] [PubMed]

35. Tomic, M.T.; Espinoza, Y.; Martinez, Z.; Pham, K.; Cobb, R.; Snow, D.M.; Earnhart, C.G.; Pals, T.; Syar, E.S.; Niemuth, N.; et al. Monoclonal Antibody Combinations Prevent Serotype A and Serotype B Inhalational Botulism in a Guinea Pig Model. Toxins 2019, 11, 208. [CrossRef]

36. Espinoza, Y.; Wong, D.; Ahene, A.; Der, K.; Martinez, Z.; Pham, J.; Cobb, R.; Farr-Jones, S.; Marks, J.D.; Tomic, M.T. Pharmacokinetics of Human Recombinant Anti-Botulinum Toxin Antibodies in Rats. Toxins 2019, 11, 345. [CrossRef]

37. Kubota-Koketsu, R.; Mizuta, H.; Oshita, M.; Ideno, S.; Yunoki, M.; Kuhara, M.; Yamamoto, N.; Okuno, Y.; Ikuta, K. Broad neutralizing human monoclonal antibodies against influenza virus from vaccinated healthy donors. Biochem. Biophys. Res. Commun. 2009, 387, 180-185. [CrossRef]

38. Pan, Y.; Sasaki, T.; Kubota-Koketsu, R.; Inoue, Y.; Yasugi, M.; Yamashita, A.; Ramadhany, R.; Arai, Y.; Du, A.; Boonsathorn, N.; et al. Human monoclonal antibodies derived from a patient infected with 2009 pandemic influenza A virus broadly cross-neutralize group 1 influenza viruses. Biochem. Biophys. Res. Commun. 2014, 450, 42-48. [CrossRef]

39. Misaki, R.; Fukura, N.; Kajiura, H.; Yasugi, M.; Kubota-Koketsu, R.; Sasaki, T.; Momota, M.; Ono, K.-I.; Ohashi, T.; Ikuta, K.; et al. Recombinant production and characterization of human anti-influenza virus monoclonal antibodies identified from hybridomas fused with human lymphocytes. Biologicals 2016, 44, 394-402. [CrossRef]

40. Torii, Y.; Tokumaru, Y.; Kawaguchi, S.; Izumi, N.; Maruyama, S.; Mukamoto, M.; Kozaki, S.; Takahashi, M. Production and immunogenic efficacy of botulinum tetravalent (A., B., E., F) toxoid. Vaccine 2002, 20, 2556-2561. [CrossRef]

41. Nowakowski, A.; Wang, C.; Powers, D.B.; Amersdorfer, P.; Smith, T.J.; Montgomery, V.A.; Sheridan, R.; Blake, R.; Smith, L.A.; Marks, J.D. Potent neutralization of botulinum neurotoxin by recombinant oligoclonal antibody. Proc. Natl. Acad. Sci. USA 2002, 99, 11346-11350. [CrossRef] [PubMed]

42. Adekar, S.P.; Takahashi, T.; Jones, R.M.; Al-Saleem, F.H.; Ancharski, D.M.; Root, M.J.; Kapadnis, B.P.; Simpson, L.L.; Dessain, S.K. Neutralization of Botulinum Neurotoxin by a Human Monoclonal Antibody Specific for the Catalytic Light Chain. PLoS ONE 2008, 3, e3023. [CrossRef] [PubMed]

43. Diamant, E.; Lachmi, B.-E.; Keren, A.; Barnea, A.; Marcus, H.; Cohen, S.; Ben David, A.; Zichel, R. Evaluating the Synergistic Neutralizing Effect of Anti-Botulinum Oligoclonal Antibody Preparations. PLoS ONE 2014, 9, e87089. [CrossRef] [PubMed]

44. Fujinaga, Y.; Sugawara, Y.; Matsumura, T. Uptake of botulinum neurotoxin in the intestine. Curr. Top. Microbiol. Immunol. 2013, 364, 45-59.

45. Kozaki, S.; Kamata, Y.; Nishiki, T.-I.; Kakinuma, H.; Maruyama, H.; Takahashi, H.; Karasawa, T.; Yamakawa, K.; Nakamura, S. Characterization of Clostridium botulinum Type B Neurotoxin Associated with Infant Botulism in Japan. Infect. Immun. 1998, 66, 4811-4816. [CrossRef]

46. Umeda, K.; Seto, Y.; Kohda, T.; Mukamoto, M.; Kozaki, S. Genetic Characterization of Clostridium botulinum Associated with Type B Infant Botulism in Japan. J. Clin. Microbiol. 2009, 47, 2720-2728. [CrossRef]

47. Yang, G.-H.; Kim, K.-S.; Kim, H.-W.; Jeong, S.T.; Huh, G.H.; Kim, J.C.; Jung, H.H. Isolation and characterization of a neutralizing antibody specific to internalization domain of Clostridium botulinum neurotoxin type B. Toxicon 2004, 44, 19-25. [CrossRef]

48. Cheng, L.W.; Henderson, T.D.; Lam, T.I.; Stanker, L.H. Use of Monoclonal Antibodies in the Sensitive Detection and Neutralization of Botulinum Neurotoxin Serotype B. Toxins 2015, 7, 5068-5078. [CrossRef]

49. Rasetti-Escargueil, C.; Avril, A.; Chahboun, S.; Tierney, R.; Bak, N.; Miethe, S.; Mazuet, C.; Popoff, M.R.; Thullier, P.; Hust, M.; et al. Development of human-like scFv-Fc antibodies neutralizing Botulinum toxin serotype B. $m A$ bs 2015, 7, 1161-1177. [CrossRef]

50. Miethe, S.; Mazuet, C.; Liu, Y.; Tierney, R.; Rasetti-Escargueil, C.; Avril, A.; Frenzel, A.; Thullier, P.; Pelat, T.; Urbain, R.; et al. Development of Germline-Humanized Antibodies Neutralizing Botulinum Neurotoxin A and B. PLOS ONE 2016, 11, e0161446. [CrossRef] 
51. Garcia-Rodriguez, C.; Geren, I.N.; Lou, J.; Conrad, F.; Forsyth, C.; Wen, W.; Chakraborti, S.; Zao, H.; Manzanarez, G.; Smith, T.J.; et al. Response re: 'Neutralizing human monoclonal antibodies binding multiple serotypes of botulinum neurotoxin'. Protein Eng. Des. Sel. 2011, 24, 633-634. [CrossRef]

52. Adekar, S.P.; Jones, R.M.; Elias, M.; Al-Saleem, F.H.; Root, M.J.; Simpson, L.L.; Dessain, S. Hybridoma populations enriched for affinity-matured human IgGs yield high-affinity antibodies specific for botulinum neurotoxins. J. Immunol. Methods 2008, 333, 156-166. [CrossRef] [PubMed]

53. Meng, Q.; Garcia-Rodriguez, C.; Manzanarez, G.; Silberg, M.; Conrad, F.; Bettencourt, J.; Pan, X.; Breece, T.; To, R.; Li, M.; et al. Engineered domain-based assays to identify individual antibodies in oligoclonal combinations targeting the same protein. Anal. Biochem. 2012, 430, 141-150. [CrossRef] [PubMed]

54. Sakaguchi, G. Clostridium botulinum toxins. Pharmacol. Ther. 1982, 19, 165-194. [CrossRef]

55. Adekar, S.P.; Segan, A.T.; Chen, C.; Bermudez, R.; Elias, M.D.; Selling, B.H.; Kapadnis, B.P.; Simpson, L.L.; Simon, P.M.; Dessain, S.K. Enhanced Neutralization Potency of Botulinum Neurotoxin Antibodies Using a Red Blood Cell-Targeting Fusion Protein. PLoS ONE 2011, 6, 17491. [CrossRef] [PubMed]

56. Sharma, R.; Zhao, H.; Al-Saleem, F.H.; Ubaid, A.S.; Puligedda, R.D.; Segan, A.T.; Lindorfer, M.A.; Bermudez, R.; Elias, M.; Adekar, S.P.; et al. Mechanisms of enhanced neutralization of botulinum neurotoxin by monoclonal antibodies conjugated to antibodies specific for the erythrocyte complement receptor. Mol. Immunol. 2013, 57, 247-254. [CrossRef]

57. Suzuki, T.; Ishii-Watabe, A.; Tada, M.; Kobayashi, T.; Kanayasu-Toyoda, T.; Kawanishi, T.; Yamaguchi, T. Importance of Neonatal FcR in Regulating the Serum Half-Life of Therapeutic Proteins Containing the Fc Domain of Human IgG1: A Comparative Study of the Affinity of Monoclonal Antibodies and Fc-Fusion Proteins to Human Neonatal FcR. J. Immunol. 2010, 184, 1968-1976. [CrossRef]

58. Hill, K.K.; Smith, T.J.; Helma, C.H.; Ticknor, L.; Foley, B.; Svensson, R.T.; Brown, J.L.; Johnson, E.A.; Smith, L.A.; Okinaka, R.T.; et al. Genetic Diversity among Botulinum Neurotoxin-Producing Clostridial Strains. J. Bacteriol. 2006, 189, 818-832. [CrossRef]

59. Kalb, S.R.; Baudys, J.; Rees, J.C.; Smith, T.J.; Smith, L.A.; Helma, C.H.; Hill, K.; Kull, S.; Kirchner, S.; Dorner, M.B.; et al. De novo subtype and strain identification of botulinum neurotoxin type B through toxin proteomics. Anal. Bioanal. Chem. 2012, 403, 215-226. [CrossRef]

60. Peck, M.; Smith, T.J.; Anniballi, F.; Austin, J.W.; Bano, L.; Bradshaw, M.; Cuervo, P.; Cheng, L.W.; Derman, Y.; Dorner, B.G.; et al. Historical Perspectives and Guidelines for Botulinum Neurotoxin Subtype Nomenclature. Toxins 2017, 9, 38. [CrossRef]

61. Beers, W.H.; Reich, E. Isolation and characterization of Clostridium botulinum type B toxin. J. Boil. Chem. 1969, 244, 4473-4479.

62. Kohda, T.; Hosomi, K.; Kozaki, S.; Nakamura, K.; Torii, Y.; Mukamoto, M. Characterization of the functional activity of botulinum neurotoxin subtype B6. Microbiol. Immunol. 2017, 61, 482-489. [CrossRef] [PubMed]

63. Kohda, T.; Ihara, H.; Seto, Y.; Tsutsuki, H.; Mukamoto, M.; Kozaki, S. Differential contribution of the residues in C-terminal half of the heavy chain of botulinum neurotoxin type B to its binding to the ganglioside GT1b and the synaptotagmin 2/GT1b complex. Microb. Pathog. 2007, 42, 72-79. [CrossRef] [PubMed]

64. Arimitsu, H.; Inoue, K.; Sakaguchi, Y.; Lee, J.; Fujinaga, Y.; Watanabe, T.; Ohyama, T.; Hirst, R.; Oguma, K. Purification of Fully Activated Clostridium botulinum Serotype B Toxin for Treatment of Patients with Dystonia. Infect. Immun. 2003, 71, 1599-1603. [CrossRef] [PubMed]

65. Reed, L.; Muench, H. A simple method of estimating fifty per cent endpoints12. Am. J. Epidemiol. 1938, 27, 493-497. [CrossRef]

66. Kondo, H.; Shimizu, T.; Kubonoya, M.; Izumi, N.; Takahashi, M.; Sakaguchi, G. Titration of botulinum toxins for lethal toxicity by intravenous injection into mice. Jpn. J. Med Sci. Boil. 1984, 37, 131-135. [CrossRef]

(C) 2020 by the authors. Licensee MDPI, Basel, Switzerland. This article is an open access article distributed under the terms and conditions of the Creative Commons Attribution (CC BY) license (http://creativecommons.org/licenses/by/4.0/). 